\title{
ESTRUTURAS EM REDE DAS ORGANIZAÇÕES E PÓLO AUTOMOTIVO NA REGIÃO DO VALE DO PARAÍBA
}

\author{
Francisco Santos Sabbadini ${ }^{1}$ \\ José Roberto Villavicencio ${ }^{2}$
}

Resumo: O Presente estudo apresenta informações para a caracterização da estrutura produtiva, das relações entre os participantes dessa estrutura e dos relacionamentos entre esses agentes, no tecnopólo de Porto Real, RJ, sob a perspectiva das estruturas em rede das organizações.

Palavras chave: Estruturas em Redes, organizações, tecnopólo automotivo, Transnacional.

\section{INTRODUÇÃO}

Com a implantação do pólo automotivo, a partir de 1997, através do consórcio modular da Volkswagen, em Resende, e posteriormente em 1998, com a decisão da Peugeot Citroen instalar uma unidade de produção de automóveis de passeio, no município de Porto Real, caracterizou-se a conformação de uma estrutura de rede empresarial de importantes empresas transnacionais, cuja atividade central é a montagem de veículos automotores para exportação. Essas decisões deslocaram a predominância da produção industrial do setor metal-mecânico e de química fina para o setor automotivo sem que a região tivesse nenhuma qualificação para oferta de produtos ou serviços às demandas destes novos entrantes.

Todavia observa-se que as políticas de desenvolvimento baseadas num modelo de atração de grandes empresas com incentivos, benefícios fiscais e facilidades, sem uma visão holística do contexto social da região, criam hiatos de desenvolvimento regional, ao mesmo tempo em que podem gerar pólos econômicos, mas não necessariamente desenvolvimento econômico.

1 Departamento de Administração de Empresas e Instituto Politécnico de Logística da Universidade Estácio de Sá. Rio de Janeiro. E-Mail: sabbadini01@yahoo.com.br

2 Departamento de Administração de Empresas e Instituto Politécnico de Logística da Universidade Estácio de Sá. Rio de Janeiro, e da Fundação Osvaldo Aranho, em Volto Redondo, Rio de Janeiro. 


\section{REVISÃO DA LITERATURA}

Esta revisão bibliográfica baseia-se na literatura sobre redes empresariais e as transnacionais, partindo-se do princípio de que as empresas procuram organizar-se de forma a obter vantagens competitivas.

\subsection{ESTRUTURAS EM REDES DE ORGANIZAÇÕES}

A necessidade de eficiência coletiva e competitividade conduziram as empresas a estabelecerem diferentes tipos de arranjos. Segundo Gurisatti (1999) são três os modelos de produção industrial, a fábrica integrada (fordista), a empresa-rede (Toyotista) e as redes de empresas (distritos industriais):

- No modelo da empresa fordista, todas as relações são governadas e dirigidas pelo planejamento da alta administração e suas decisões. Portanto, toda a cadeia produtiva está subordinada a governança da empresa. Nesse modelo há baixa participação no processo decisório e na geração de inovação. Os lucros são concentrados na grande organização e o processo de inovação se torna mais lento.

- Na empresa-rede (modelo toyotista), também ficam nas mãos de um único líder as funções de planejamento e relacionamento com o mercado havendo, entretanto, uma descentralização da produção e a formação de uma rede de fornecimento subordinada à esse líder. Os fornecedores possuem certo grau de participação, de natureza técnica, e uma distribuição parcial dos lucros.

- Nas redes de empresas (distritos industriais), pela sua natureza, mercado, projeto de produto, processo decisório, lucros e investimentos são subdivididos entre um grande número de operadores e, principalmente, entre os empresários da linha de frente. Há uma divisão precisa de tarefas. O grau de participação dos diversos agentes no processo é elevado e exige permanente participação dos empresários no jogo e na escolha da cadeia de valor dentro do distrito.

Segundo Porter (1999), uma aglomeração se constitui na concentração geográfica de um conjunto de empresas inter-relacionadas e instituições correlatas, vinculadas por elementos comuns e complementares. Esses aglomerados assumem diversas formas com variado grau de profundidade e sofisticação, incluindo varias empresas fornecedoras, instituições especializadas, instituições governamentais, agências de normalização e outras dedicadas à educação, informação, pesquisa e suporte técnico.

Segundo Romero (2003), essas aglomerações são caracterizadas como clusters que incluem canais de integração vertical e horizontal, relacionamentos, fabricantes de produtos complementares, infra-estrutura especializada e instituições que provêm informação e conhecimento através da educação, pesquisa, treinamento especializado e suporte técnico.

Segundo BENKO (2002, p. 154):

"O tecnopólo é a reunião, num mesmo local, de atividades de alta tecnologia, centros de pesquisa, empresas e universidades, assim como de organismos financeiros que facilitem os contatos pessoais entre esses meios, produz efeito de sinergia dos quais podem surgir idéias novas, inovações técnicas, suscitando portanto a criação de empresas". 
No caso de Porto Real, o conceito de tecnopólo apresentado acima serve como referência de análise, assim como o modelo de empresa-rede apresentado por Gurisatti (1999), o conceito de aglomeração de Porter (1999) e o conceito de cluster de Romero (2003).

Uma distinção importante para caracterizar a região econômica de Porto Real e Resende é a diferença entre pólo e cluster. Diferentemente do cluster, o pólo restringe-se a localização geográfica de um aglomerado ou conjunto de indústrias. O conceito de cluster considera a participação de um conjunto de atores de maneira coordenada e ordenada. (ROMERO, 2003).

Para identificar e caracterizar o tipo de rede existente no tecnopólo de Porto Real é necessário conhecer a estrutura de rede. Segundo Villela et al (2004, apud BRITO, 2002), os elementos estruturantes são os nós, as ligações , os fluxos e as posições. A conformação da rede é resultado da forma como se conectam os nós. Os nós são organizações ou atividades, as ligações são os relacionamentos entre as organizações, as posições são as estruturas de divisão do trabalho e os fluxos referem-se aos bens e informações.

Segundo Brito (2002), os tipos de estrutura em rede são: Programas de cooperação específicos, alianças estratégicas entre empresas, sistemas flexíveis de produção baseados em cooperação de empresas do mesmo ramo, processos de subcontratação e terceirização em determinadas especialidades ou atividades e distritos industriais.

\subsection{EMPRESAS TRANSNACIONAIS}

Segundo Gonçalves (2002), a empresa transnacional tem como característica básica possuir vantagens específicas e ser uma grande empresa, responsável pela reprodução em escala global da dinâmica capitalista resultante da convergência de três processos:

- Processos de internacionalização da produção, através de exportação, licenciamento de ativos e investimento externo direto, justificada por fatores locais como a existência de fontes de recursos de produção com custos reduzidos.

- Centralização e concentração do capital, decorrentes da forma de produção capitalista que requerem emprego em escala maior e a absorção dos pequenos capitalistas pelos maiores;

- Destruição criadora (sistema schumpeteriano de inovação), como resultado da inovação em produtos, tecnologias de produção e transporte, novos mercados e novas formas de organização industrial criadas pela empresa.

\section{REGIÃO SUL FLUMINENSE: CARACTERIZAÇÃO}

A região sul fluminense, mais especificamente a micro-região do médio Paraíba na qual estão incluídas a cidade de Volta Redonda, Barra Mansa, Resende, Itatiaia e Porto Real, historicamente tem sua economia baseada na indústria de transformação como atividade econômica preponderante.

A Região Sul Fluminense (Médio Paraíba) é, conforme dados do CIDE, a terceira maior entre as regiões administrativas de planejamento do Estado do Rio de Janeiro, 
com tradição em siderurgia e metalurgia, especialmente devido à presença da CSN Companhia Siderúrgica Nacional - situada no município de Volta Redonda e de química fina como a presença do grupo Sandoz e Ciba-Gigy em Resende.

A infra-estrutura conta com 10 instituições de ensino superior locais, abrangendo faculdades e centros universitários, duas universidade (Estácio de Sá, UniFOA, UBM, UERJ entre outras), unidades de formação profissional do SENAI e SENAC e uma agência do SEBRAE.

A economia da região está baseada na indústria de transformação, com $48,45 \%$ da participação no produto da indústria no sul fluminense e na indústria química, com 20,07\%, conforme dados do CIDE de 2001, conforme o gráfico n 1

\section{Participação \% no PIB da Região Sul Fluminense ano 2001}

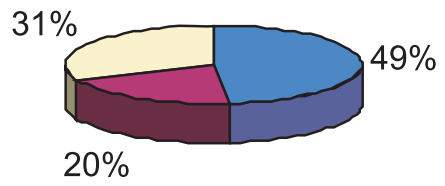

$\square$ Metalúrgia e
siderurgia
$\square$ Química
$\square$ Demais setores

Fonte: CIDE, 2001. Os demais setores compreendem Produtos alimentares, minerais não metálicos, material eletroeletrônico, papel e gráfica, bebidas, farmacêutica, máquinas e equipamentos e vestuário.

Uma avaliação da evolução do PIB dos municípios da região econômica relacionada ao pólo automotivo permite verificar que a indústria automotiva promoveu o aumento da atividade econômica e o aumento do produto regional.

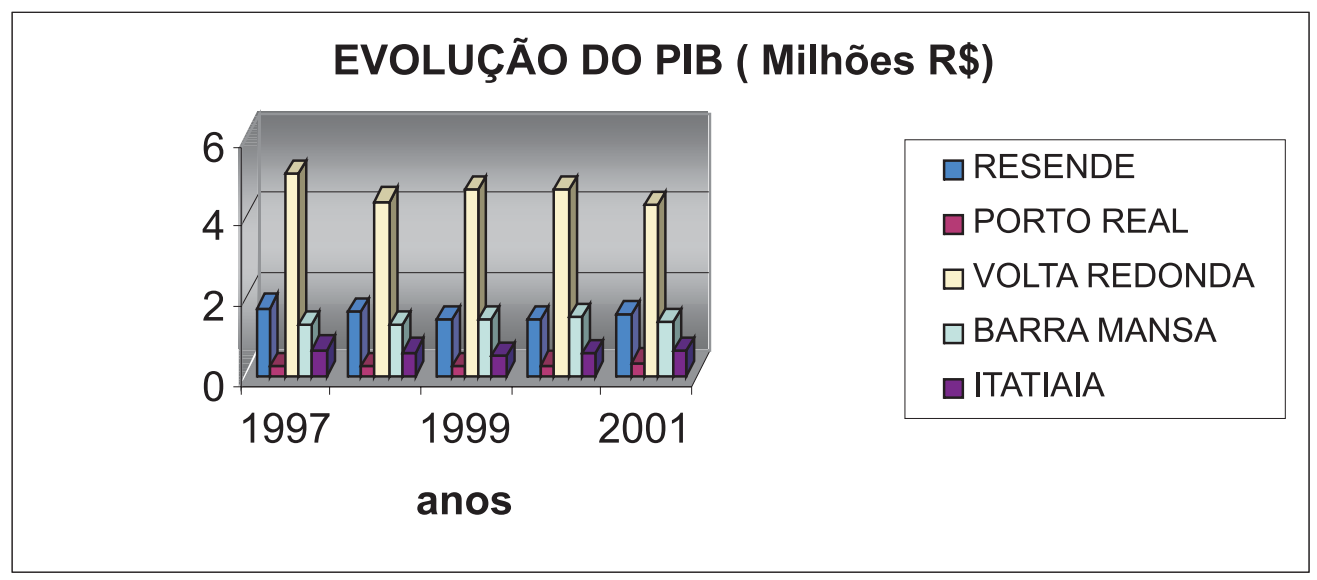

Fonte: Alvarez, et al., 2002. 
O perfil destas indústrias, quanto ao porte, apresenta uma predominância quantitativa de pequenas empresas, sendo de apenas $1 \%$ o número de grandes corporações. $A$ realização dos investimentos automotivos, entretanto, segundo Alvarez et al (2002), não gerou indícios de desenvolvimento nas empresas locais pelo fornecimento local, em grande parte devido à falta de qualificação e preparo técnico para atender as demandas do setor na região.

\section{PSA PEUGEOT CITRÖEN E O TECNOPÓLO DE PORTO REAL}

O Grupo PSA Peugeot Citröen, que neste trabalho será chamada apenas como Peugeot, é o sexto produtor mundial de automóveis, com uma participação de $5 \%$ do mercado mundial. No Brasil as operações iniciaram-se em 2001, no CPPR, Centro de Produção de Porto Real

O Tecnopólo é a área dentro da mesma locação industrial, localizada no entorno do Centro de Produção, abrigando os fornecedores sistemistas (de primeira camada).

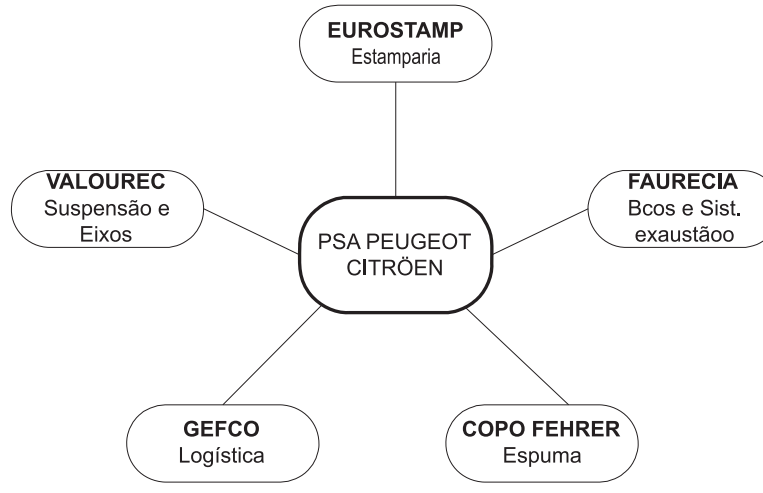

Figura 2: Tecnopólo de Porto Real - CPPR

- Regime de funcionamento e coordenação

O regime de funcionamento é na forma de condomínio industrial, onde todos os custos fixos relativos à manutenção da infra-estrutura e das utilidades (água, saneamento, energia, telecomunicações, etc) são rateados entre os integrantes do aglomerado.

São definidas as práticas e as linhas gerais que disciplinam a forma de relacionamento e coordenação das atividades entre os membros. A administração do condomínio é gerida a cada ano por um integrante e funciona como intermediária entre o tecnopólo e os demais atores da região. (Fonte: entrevista)

- Processo de fabricação:

O processo de fabricação abrange três etapas: montagem bruta (solda), pintura e montagem final, sendo realizado pela Peugeot. Os fornecedores não participam diretamente O planejamento, gerenciamento, coordenação e execução do processo de produção fica a cargo da Peugeot, que estabelece as especificações técnicas, critérios de qualidade e excelência. 
- Rede de suprimentos

A configuração de rede de suprimentos é essencialmente concentrada em empresas no Estado de São Paulo, tendo apenas um fornecedor no Estado do Rio de Janeiro, além dos cinco sistemistas: Michelin em Itatiaia. Grande parte dos componentes são importados, tendo em vista o baixo grau de nacionalização dos veículos fabricados pela empresa.

Essa situação se deve ao fato de as empresas da região do Médio Paraíba terem desenvolvido competências para o fornecimento de séries limitadas e serviços de manutenção industrial, porém pouco preparadas para atender as exigências da manufatura automotiva. Na região foram detectadas apenas 02 empresas pertencentes ao setor de autopeças para efetuar a oferta local (ALVAREZ et al, 2002).

Estes fornecedores da primeira camada, por estarem instalados no "território" da Peugeot, trazem um diferencial competitivo, uma vez que, os produtos destes sistemistas são entregues ao cliente on-demand, conseqüentemente não havendo necessidade de estoques por parte da Peugeot nestes itens.

\section{- Política de suprimentos}

A política de suprimentos é focada na redução dos custos, baseada numa estratégia de trabalhar com poucos fornecedores que se responsabilizem integralmente pelo atendimento das demandas da Peugeot.

O perfil definido pela empresa é que seus fornecedores devem ter os seguintes requisitos: 1) ser globais; 2) ter foco no setor automobilístico; 3) ter capacidade de desenvolvimento próprio devendo atender a seis categorias de fatores de excelência: a)Pesquisa e desenvolvimento; b) Qualidade; c) Logística; d) Perenidade; e) Internacionalização e f) Produtividade e preço.

O perfil e os fatores de excelência devem atingir a toda a cadeia de fornecimento, entretanto o foco é nos fornecedores de primeira camada e, em casos críticos, também nos de segunda camada.

- Seleção de fornecedores e contratos

Os fornecedores assinam termos de compromisso quando do fechamento de contratos com a empresa, incluindo um protocolo logístico, condições de desempenho, cumprimento de metas. Não há cláusula de exclusividade.

\section{- Subcontratação}

Nas entrevistas foi constatado que há processos de terceirização e em alguns casos de quarteirização, identificados nos serviços auxiliares, como manutenção, locação de mão-de-obra, limpeza e conservação.

\section{- Estratégias e processos}

Segundo Alvarez et al (2002), as montadoras do setor automotivo adotam uma série de estratégias. No tecnopólo a Peugeot utiliza as seguintes estratégias que determinam a forma de atuação e competição:

a) Aceleração do ritmo de introdução de novos modelos.

b) Organização e focalização em plataformas de produtos, com o intuito de racionalizar custos, obtendo ganhos de escala, escopo e flexibilidade;

c) Crescimento do conteúdo tecnológico agregado ao veículo. Essa estratégia tem modificado a pauta de compras da montadora e dos fornecedores, além de aumentar a necessidade de investimentos em P\&D por parte dos fornecedores. 
Há intercâmbio entre os sistemistas e a Peugeot (Fonte: entrevistas).

d) Fabricação modular, simplificando o processo de montagem final e reduzindo custos. A Peugeot tem trabalhado intensivamente nesse aspecto, através da desverticalização de produção.

e) Desverticalização da produção;

f) Integração da cadeia de suprimentos através da WEB. Antes do início das atividades no Tecnopólo de Porto Real, todos os fornecedores tiveram que ajustar seus sistemas de ERP, EDI, e outros sistemas corporativos, aos respectivos padrões da Peugeot.

g) Trabalhar com distintos modelos de fornecimento simultaneamente.

\section{TECNOPÓLO E AGENTES INSTITUCIONAIS}

Os principais atores existentes na região ou no Estado do Rio de Janeiro sejam privados, institucionais, agências de fomento ou esferas governamentais, estão descritos a seguir:

- Prefeitura de Porto Real e de Resende: representantes do Poder Público e principais atores para promover as parcerias Público-Privadas.

- SENAI: Parceria no treinamento e qualificação de recursos humanos. A Peugeot equipou o SENAI de Resende com os recursos e equipamentos necessários e informações tecnológicas que foram incorporadas ao acervo de conhecimentos deste.

- Instituições de ensino: Existe alguma parceria entre as Instituições de ensino e o Pólo, no sentido de abrir oportunidades aos formandos das instituições da região. O tecnopólo absorve a mão-de-obra qualificada por elas: UERJ (Resende), Universidade Estácio de Sá (Resende), Fundação Osvaldo Aranha - V. Redonda, Centro Universitário de Barra Mansa, porém inexiste parcerias de Pesquisa e Desenvolvimento, uma vêz que estes atores não estão preparados para a mesma.

- EADI (Estação Aduaneira do Interior). Utilizada como centro de importação de componentes e exportação de veículos, pela Peugeot e sistemistas.

- Incubadora de empresas (UERJ): não há ligação entre o tecnopólo e a incubadora de empresas existente na região.

- SEBRAE/RJ. Há estudos do Sebrae/RJ sobre arranjos produtivos locais, entretanto não há na região nenhuma ação efetiva no sentido de desenvolver competência ou uma rede de pequenas e médias empresas, vinculadas ao setor automotivo.

- A GEFCO, uma das sistemistas do tecnopólo que presta serviços de transporte para empresas do pólo como Pernod Ricard, antiga Seagram; e Guardian, Fábrica de vidros em Porto Real. (Fonte: entrevista) 


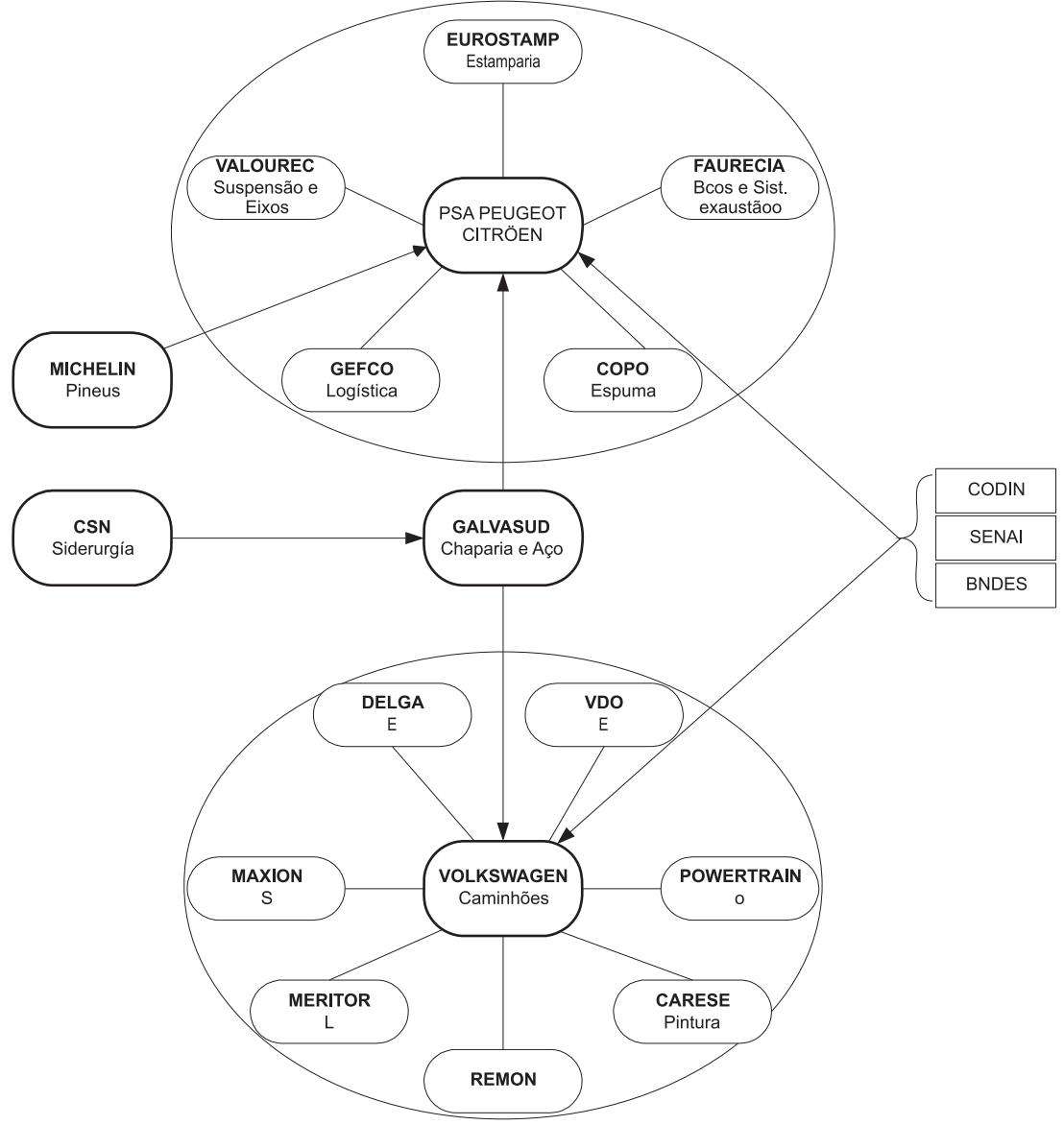

Figura 3: Relacionamento entre o Pólo e o ambiente TECNOPÓLO - CONSÓRCIO MODULAR

\section{CONSIDERAÇÕES FINAIS}

As questões tratadas neste trabalho relativas ao tecnopólo de Porto Real, as formas de coordenação produtiva, os elementos conceituais que fundamentaram esta análise, e de maneira mais geral, os desdobramentos em termos das ligações e dinâmicas dos atores envolvidos, podem ser analisados sob diversos aspectos.

O tecnopólo é um aglomerado industrial, baseado na lógica da manufatura automotiva, tendo o Grupo PSA Peugeot Citroën, aqui tratado por Peugeot, como coordenador das atividades e principal cliente.

A Peugeot, sendo uma empresa transnacional, busca vantagens específicas que reproduzam o regime de acumulação do capital, propiciem economias de escopo e escala, 
através de: 1) Vantagens locacionais, abrangendo infra-estrutura; 2) internacionalização da produção, através de exportação, licenciamento de ativos e investimento externo direto; 3) centralização e concentração do capital; 4) destruição criadora (sistema schumpeteriano de inovação), como resultado da inovação em produtos, tecnologias de produção e transporte, novos mercados e novas formas de organização industrial criadas pela empresa.

Esses fatores estão presentes não somente na forma como estrutura sua produção, como também na determinação da empresa em escolher a região de Porto Real, baseada em incentivos fiscais, infra-estrutura já existente, que viabilizaram em termos de vantagens de custos, logística e produção a sua implantação.

Uma avaliação da evolução do PIB dos municípios da região econômica relacionada ao pólo automotivo permitiu verificar que a indústria automotiva promoveu o aumento da atividade econômica e o aumento do produto regional.

Com o sistema de produção organizado na forma de empresa-rede, a Peugeot assume a função de líder, cuidando da coordenação da produção, planejamento, relacionamento com o mercado e a rede de fornecimento situada no tecnopólo. A governança pela Peugeot fica evidente tanto no processo de seleção e qualificação dos fornecedores, quanto nas políticas e estratégias adotadas pela empresa: gestão de suprimentos, estabelecimento de contratos condicionais, que salvaguardam a empresa e minimizam seus custos de transação; e na busca de maior eficiência operacional.

Em função do modelo operacional adotado pela Peugeot, a mesma consegue, na atual economia, fazer frente às mudanças mercadológicas, através do uso intensivo de Tecnologia da informação (TI) entre ela e seus fornecedores, e na esfera econômica pela redução de capital de giro em estoques, permitido pelo arranjo (lay out) operacional que mantém um fluxo contínuo de fornecimento sob demanda. A combinação destes dois fatores (técnico e econômico) confere à mesma um diferencial num segmento de mercado altamente competitivo.

A caracterização da empresa-rede Peugeot e do tecnopólo em termos de ligações e fluxos, consideradas as limitações deste trabalho, deixa evidente ligações entre fornecedores e agentes que atendem aos objetivos do aglomerado, havendo dentro do tecnopólo fluxo de informação e conhecimento pelo compartilhamento de software e tecnologia.

Uma ligação que permite transferência e incorporação de conhecimento fora do arranjo é através do capital estrutural que vai sendo formado pelo SENAI, que faz o treinamento e qualificação dos recursos humanos.

A contribuição deste trabalho está na realização de uma abordagem objetiva para auxiliar na caracterização e compreensão do processo de configuração do tipo de rede relacionado a um caso de organização industrial em rede no setor automotivo. No mesmo sentido, a partir dessa abordagem inicial, contribui no intuído de estimular o aprofundamento dos estudos relacionados ao tema. 


\section{REFERÊNCIAS}

ABREU, Alice Rangel de Paiva; RAMALHO, José Ricardo. A indústria automobilística brasileira e a implantação de novos pólos de desenvolvimento regional - o caso do Rio de Janeiro. In III Congresso LatinoAmericano de Sociología del Trabajo. Buenos Aires , 2000. Disponível em: http://www.alast.org/PDF/Walter1/Tec.AbreuyRamalho.PDF. Acesso em: 11 ago. 2004.

ADTP. Indústria automobilística: Rio terá $\mathrm{R} \$ 1,8$ bi da indústria automobilística. Disponível em: http://www.adtp.org.br/notícia.asp?id_notícia=4630. Acesso em: 02 ago. 2004.

AEDB/CPPGE. Projeto: Estudos da concentração industrial e os efeitos de polarização nos municípios de Resende e Porto Real, no período de 1994 a 1999. Levantamentos prospectivos do projeto realizados pela Associação Educacional D. Bosco, através do Centro de Pesquisa, Pós-Graduação e Extensão, Resende, dezembro 1999.

ALVAREZ, R.; PROENÇA, A.; ANDÉREZ, D. Rio automotivo: elementos da realidade e perspectivas de desenvolvimento. Rio de Janeiro: SEBRAE, 2002.

BENKO, G. Economia, espaço e globalização na aurora do século XXI. São Paulo: Hucitec, 2002.

BNDES. BNDES financia com R $\$ 24$ milhões fábrica de motores da Peugeot Citröen em Porto Real. Disponível em: http://www.bndes.gov.br/notícias/not540.asp. Acesso em: 02 ago. 2004.

BRITTO, J.N.. Diversificação, competências e coerência produtiva. KUPFER, D. e HASENCLEVER, L. (orgs). Economia Industrial: fundamentos teóricos e práticos no Brasil. Rio de Janeiro: Campos, 2002.

FIANI, R. Teoria dos custos de transação. KUPFER, D.; HASENCLEVER, L. (orgs). Economia industrial: fundamentos teóricos e práticos no Brasil. Rio de Janeiro: Campus, 2002.

GONÇALVES, Reinaldo. A empresa Transnacional. KUPFER, D.; HASENCLEVER, L. (orgs). Economia industrial: fundamentos teóricos e práticos no Brasil. Rio de Janeiro: Campus, 2002.

GURISATTI, Paolo. O nordeste italiano: nascimento de um novo modelo de organização industrial. In Empresários e empregos: o caso da terceira Itália. (COCO, G.; GALVÃO, A P.;

PORTER, Michael E. Competição: estratégias competitivas essenciais. Rio de Janeiro: Campus, 1999.

ROMERO, Elsa Ivoneth C. Desenvolvimento de clusters na visão do conhecimento: proposta do modelo PRUGI de análise: oportunidades para o Norte do Estado do Rio de Janeiro. Tese de doutorado. Rio de Janeiro : COPPE/UFRJ, 2003. 
VILLELA, Lamounier Erthal; FANDIÑO, Antonio Martinez; SEGRE, Lídia Micaela; CASTRO JR.; Joel de L. Pereira. O papel e o potencial das instituições no desenvolvimento do arranjo produtivo local do setor de confecções de moda íntima de Nova Friburgo/RJ. Material disponibilizado nas aulas da cadeira de redes empresariais, do Mestrado em Administração e Desenvolvimento Empresarial. Rio de Janeiro. Unesa. 2004.

Endereços eletrônicos consultados:

CIDE. Disponível em: http://www.cide.rj.gov.br

\title{
NETWORK STRUCTURES OF ORGANIZATIONS AND AUTOMOTIVE POLE IN THE REGION OF THE PARAÍBA VALLY
}

\begin{abstract}
This paper presents information for the characterization of the productive structure, the relationship among the participants of this structure and of the relationships among these agents, in Porto Real technological region, Rio de Janeiro State, under the perspective of the structures of organizations network.
\end{abstract}

Key-words: network structures, organizations, automotive technological region, transnational 